\title{
Molecular Orbital Study on the Polarographic Reduction of Substituted Fulvenes ${ }^{t}$
}

\author{
Noboru Takeno, Nobuhiro Takano and Mutsuo Morita \\ Muroran Institute of Technology; Mizumoto-cho, Muroran-shi, Japan
}

The halfwave potentials of 6-phenylfulvene, 6-methyl-6-phenylfulvene, 1-benzylideneindene, 9-benzylidenefluorene, and their derivatives with $p$-methyl, $p$-methoxy, and $p$ - $N, N$-dimethylamino substituents on the phenyl group were studied in relation to the lowest vacant molecular orbital energies which were calculated on the basis of the LCAO-MO methods. The parameters of coulomb and resonance integrals for hetero atoms which were proposed by Streitwieser and Zweig were adopted.

The linear relationship between the halfwave potentials and the lowest vacant molecular orbital energies by HMO method gave the correlation coefficient of 0.959 . Furthermore, the results using $0.9 \beta$ and $1.1 \beta$ as resonance integrals for essential single bonds and essential bouble bonds, respectively, in HMO calculations gave better linear relationship with correlation coefficient of 0.992 .

$\dagger$ Reactions of Fulvenes. VI.

（日本化学会誌，1972，p.985～987）

\section{カダレンおよび 1, 4,6-トリメチルナフタレンの合成}

(1971年 12 月 27 日受理)

安達 和 郎*

セスキテルペン化合物の脱水素で得られるカダレン1)は種なな 方法で合成されている2)。著者は今回ニトリルと Grignard 試薬 との反応でケトンを得，これを利用して新しい径路でカダレンお よび 1, 4,6-トリメチルナフタレンを合成した。 フェノン[1] から新化合物 2-(1-p-トリルエチル)マロン酸ジエ チル[4]および 2-(1-p-トリルエチル)、ロン酸 [5]を経て 4(p-トソル)パレロニトリル[9]を導き，９］とヨウ化メキル マグネシウムとの反応で 5-(p-トリル)-2-ヘキサノン [12 a ]を 得た。臭化イソプロピルマグネシウムとの反応では新化合物 2メキルー6-(p-トリル)-3ーヘプタノン [12 b] を生じた。[12 a $]$ お。 よび [12 b] から対応するアルコール，テトラリン誘導体を経て

* 大阪工業大学底用化学科，大阪市旭区大宮

1) a) J. Simonsen, “The Terpenes", Cambridge(1961) Vol. III, p. 4.

b) 池田鉄作, “大有機化学（第 7 巻）脂環式化合物 II”, 朝合 (1959) p. 177.

2）たとえば，

a) L. Ruzicka, C. F. Seidel, Helv. Chim. Acta, 5, 369 (1922).

b) J. C. Bardhan, S. K. Banerji, J. Chem. Soc., 1935 , 476.

c) W.S. Johnson, A. R. Jones, J. Amer. Chem. Soc., 69, 792(1947).

d) N.S. Gill, F. Lion, ibid., 72, 3468(1950).

e) 安達和郎, 日化, 89, 1264(1968).
それぞれ 1，4，6-トリメチルナフタレンおよびカダレンを得た。 また[g]から 4,7-ジメキル-1,2,3，4-テトラヒドロナブタレンー 1ーオン〔11]を経てカダレンを合成した。

\section{1 㝢験および結果}

\subsection{2-(1-p-トリルエチル)マロン酸ジエチル [4]} p-メチルフセトフェノン[1]は Adams らの方法" に準してて

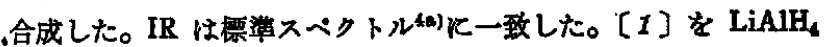
で還元し 1-(p-トyル)エタノール[2]を得た。IR は標草ス ペクトル(b)(s)K一致した。[2]を $48 \% \mathrm{HBr}$ て処理して $p$-(1ブロモエチル)トルエン〔3]を得た。エタノール中ですロン酸 ジェチル $93.5 \mathrm{~g}(0.585 \mathrm{~mol})$ と〔3]97.1 g $(0.488 \mathrm{~mol})$ を樎 合し 2-(1-p-トリルエチル)マッン酸ジエチル[4]126.6 g (93.2

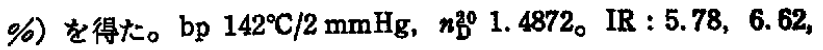
$6.84,7.29,12.20 \mu_{0}$

分析值 C $68.80 \%$, H 8.02\%
$\mathrm{C}_{16} \mathrm{H}_{22} \mathrm{O}_{4}$ としての訊算值 C $69.04 \%$ ，H 7.97\%

3) R. Adams, C. R. Noller, "Organic Syntheses", Coll. Vol. I, p. 109(1948).

4) "Sadtler Standard Spectra", Sadtler Research Laboratories, Philadelphia. a) No. 872, b) No. 24444.

5）日本赤外データ委買会, “IRDC カード”, 南江堂, a) Na 1461, b) No. 10772 . 


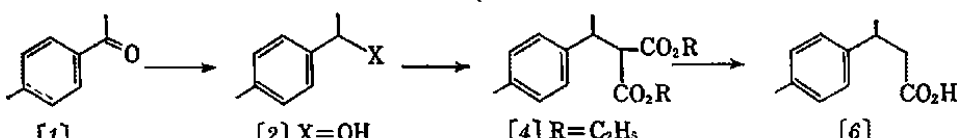

[1]

[2] $\mathrm{X}=\mathrm{OH}$

[4] $\mathrm{R}=\mathrm{C}_{2} \mathrm{H}_{5}$

[6]<smiles>[Y][R11]([H])([H])Br</smiles>

[8] $\mathrm{X}=\mathrm{Br}$

[10]

[11] 0

$[9] \mathrm{X}=\mathrm{CN}$<smiles>[R]C(=O)CCCc1ccc(C)cc1</smiles>

$[12 \mathrm{a}, \mathrm{b}]$

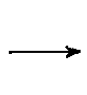<smiles>[R]C(O)CCC(C)c1ccccc1</smiles>

$[13 \mathrm{a}, \mathrm{b}]$<smiles>CC=C1CCC(C)c2ccc(C)cc21</smiles><smiles>Cc1ccc(I)c2ccc(I)cc12</smiles>

a: $\mathrm{R}=\mathrm{CH}_{3}$

b: $\mathrm{R}=\mathrm{CH}\left(\mathrm{CH}_{3}\right)_{2}$

\subsection{3 -(p-トリル) 酪酸【6]}

[4]をエタノール中 KOH でケン化した。過㮃のアルカリを 中和するとモノカリウム塩 (分解点 191 $192^{\circ} \mathrm{C}$ ) が析出した。塩 酸酸性にして 2-(1-p-トリルエチル)マロン酸 [5]を得た。結 晶性微粉末， $\mathrm{mp} 146^{\circ} \mathrm{C}$ (分解) (ベンゼン)。 IR : 5.80，6.62， $12.25 \mu_{\mathrm{o}}$

\section{分析値 C $64.66 \%$, H $6.41 \%$}

$\mathrm{C}_{12} \mathrm{H}_{14} \mathrm{O}_{4}$ としての部算值 C $64.85 \%, \mathrm{H} 6.35 \%$

[5]を脱炭酸して 3-(p-トソル)酪酸 [6]を得た。葉状結

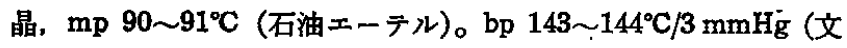
献值" $\mathrm{mp} 91^{\circ} \mathrm{C}$, bp $165^{\circ} \mathrm{C} / 10 \mathrm{mmHg}$ )。

\section{$1.34-(p-ト リ ル) ハ$ ハレロトリル [9]}

[6]を $\mathrm{LiAlH}_{4}$ で還元し3-(p-トリル)-1-ブタノール[7]を 得た。bp $108^{\circ} \mathrm{C} / 3 \mathrm{mmHg}$ (文嘀値") bp $150^{\circ} \mathrm{C} / 15 \mathrm{mmHg}$ ), $n_{\mathrm{D}}^{20}$ 1.5162。[7]を $\mathrm{HBr}$ 氷酸酸溶液と封管中で加熱し 1-ブロモー 3-( $p$-トリル)ブタン[8]を得た。 bp $103^{\circ} \mathrm{C} / 3 \mathrm{mmHg}$ (文献値”) bp $\left.140^{\circ} \mathrm{C} / 20 \mathrm{mmHg}\right), n_{\mathrm{D}}^{20} 1.5340_{\text {。 }}$ [ 8 ] $71 \mathrm{~g}(0.313 \mathrm{~mol})$ $\mathrm{KCN} 42 \mathrm{~g}(0.627 \mathrm{~mol})$ とエタンール中で還流し 4 -( $(p-$ トリル) パレロニトyル[9]53.1 g(98.0\%) を得た。bp $119^{\circ} \mathrm{C} / 3 \mathrm{mmHg}$ ， $n_{\mathrm{D}}^{20} 1.5100$ 。 IR : 4. 45, 6.62, 6.88, 7.24, $12.18 \mu_{\text {。 }}$

$$
\text { 分析値 C } 83.22 \%, \mathrm{H} 8.63 \%, \mathrm{~N} 8.08 \%
$$

$\mathrm{C}_{12} \mathrm{H}_{15} \mathrm{~N}$ としての計算値 C $83.19 \%, \mathrm{H} 8.73 \%$, N 8.09\%

1.4 4, 7-ジメチル-1, 2, 3, 4-テトラヒドロナフタレン-1-オン [II]

[9]を希硫酸で加水分解し， $\mathrm{NaOH}$ 水溶液で抽出して 4-( トリル)吉草酸 [10]を得た。bp 149 $150^{\circ} \mathrm{C} / 3 \mathrm{mmHg}$ (文献値”) bp $\left.155^{\circ} \mathrm{C} / 0.5 \mathrm{mmHg}\right), n_{\mathrm{D}}^{20} 1.5128$ 。[10] から得た酸塩化物をへ ソゼン中 $\mathrm{SnCl}_{4}$ で環化し 4, 7-ジメチル-1, 2,3，4-テトラヒドロナ フタンンー1ーオン [11] を得た。bp $119^{\circ} \mathrm{C} / 3 \mathrm{mmHg}$ (文献值 ${ }^{7}$ bp $157 \sim 160^{\circ} \mathrm{C} / 15 \mathrm{mmHg}$ )， $n_{\mathrm{D}}^{20} 1.5560$ 。セミカルバン゙ン，微細なブ ツズム状結晶, $\mathrm{mp} 194 \sim 195^{\circ} \mathrm{C}$ (エタノール)。2,4-ジニトロフェ ニルヒドラゾン, 赤色針状結晶, $\mathrm{mp} 236 \sim 237^{\circ} \mathrm{C}$ (トルエン)。

6) H. Rupe, Fr. Wiederkehr, Helv. Chim. Acta, 7, 654 (1924).

7) L. Ruzicka, L. Ehmann, ibid., 15, 140(1932).

\section{$1.5 \mathrm{~g}$ に・リルと Grignard 試菜との反応}

ヨウ化メチル $18.5 \mathrm{~g}(0.13 \mathrm{~mol})$ から調製した Grignard 試薬

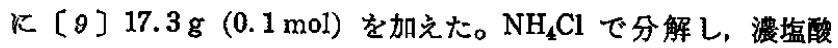
$100 \mathrm{~m} l$ を加兄て薏沸 L，5-( $p$-トリル)-2-ヘキサノン [12 a] $7.0 \mathrm{~g}(36.8 \%)$ を得た。bp $110 \sim 115^{\circ} \mathrm{C} / 4 \mathrm{mmHg}_{\text {。 }} \mathrm{IR}: 5.84$, $6.62,6.90,7.39,12.20 \mu$ 。ミ゙ルバン゙ン, ウロコ状結晶, mp 156 $157^{\circ} \mathrm{C}$ (エタノール) (文献值 ${ }^{8)} \mathrm{mp} 142^{\circ} \mathrm{C}$ )。2,4-ジニ ロフェニルヒドラゾン, 黄色結晶, mp 95 96 ${ }^{\circ} \mathrm{C}$ (ベンゼン)。

臭化イソプロピル $16.2 \mathrm{~g}(0.13 \mathrm{~mol})$ から調整した Grignard 試薬を同侎に〔9]と反応させて 2-メキルー6-(p-トリル)-3-へ プタフン $[12 \mathrm{~b}] 3.8 \mathrm{~g}(17.4 \%)$ を得た。bp $154 \sim 165^{\circ} \mathrm{C} / 5 \mathrm{mmHg}$ 。 IR : $5.84,6.62,6.85,7.22,7.32,12.20 \mu$ 。

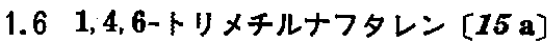

[12 a] を LiAlH $_{4}$ で道元し, 5-(p-トリル)-2-ヘキサノール [13 a] を得た。 bp $119 \sim 123^{\circ} \mathrm{C} / 4 \mathrm{mmHg}$ 。[13 a] を $91.5 \% \mathrm{H}_{2} \mathrm{SO}_{4}$

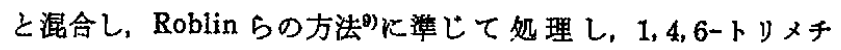
ル-1, 2, 3, 4-テトラヒドロナフタレン〔14a] を得た。bp 93〜 $95^{\circ} \mathrm{C} / 4 \mathrm{mmHg}$ 。[14 a] をイオウで脱水素し，粗炭化水素を得た。 ピクラート，橙色針状結晶, $\mathrm{mp} 132 \sim 133^{\circ} \mathrm{C}$ (文献值 ${ }^{\eta} \mathrm{mp} 133^{\circ} \mathrm{C}$ )。 スチフォート, 黄色結晶, $\mathrm{mp} 112 \sim 113^{\circ} \mathrm{C}$ (文献値 ${ }^{7)} \mathrm{mp} 114^{\circ} \mathrm{C}$ )。 2, 4,7-トリニトロフルオレノン錯体, 橙褐色結晶, mp 147 $148^{\circ} \mathrm{C}_{\text {。 }}$

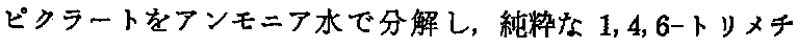
ルナフタレン [15 a] を得た。bp $122^{\circ} \mathrm{C} / 5 \mathrm{mmHg}$ (文献值”) bp $\left.140 \sim 142^{\circ} \mathrm{C} / 15 \mathrm{mmHg}\right), d_{4}^{20} 0.9975, n_{\mathrm{D}}^{20} 1.6038$ 。NMR : 2.48 ppm (一重線, $3 \mathrm{H}, \beta-\mathrm{CH}_{3}$ ), $2.55 \mathrm{ppm}$ (一重線, $6 \mathrm{H}, \alpha-\mathrm{CH}_{3}$ ), $6.95 \sim 7.90 \mathrm{ppm}$ (多重線, $5 \mathrm{H}$ ，芳香環ブロトン)。

\section{7 カダレン $[15 \mathrm{~b}]$}

[12b]を還元して得た bp $130 \sim 136^{\circ} \mathrm{C} / 4 \mathrm{mmHg}$ の 2-メチルー 6-(p-トリル)-3-ヘプタノール[13b]を $91.5 \% \mathrm{H}_{2} \mathrm{SO}_{4}$ で処理 して bp 108 114 ${ }^{\circ} \mathrm{C} / 4 \mathrm{mmHg}$ の 1, 6-ジメキル-4-イソプロピルー $1,2,3,4$-テトラヒドロナフタレン [14 b]を得，イオウで脱水装 して粗カダレンを得た。

8) H. Rupe, Fr. Schüß, Helv. Chim. Acta, 9, 992(1926).

9) R. O. Roblin, Jr. D. Davidson, M. T. Bogert, J. Amer. Chem. Soc., 57, 151(1935). 
〔11〕に臭化イソプロピルマグネシウムを反応させ、イオウで 脱水素して粗カダレンを得た。

ピクラート， mp $114 \sim 115^{\circ} \mathrm{C}$ (文献值 ${ }^{2 a) 2 e)} \mathrm{mp} 114 \sim 115^{\circ} \mathrm{C}$ )。 スチフナート， $\mathrm{mp} 138 \sim 139^{\circ} \mathrm{C}$ (文献值 $\mathrm{mp} 138 \sim 139^{\circ} \mathrm{C}^{2 \mathrm{e}}$ ), 139 $\left.{ }^{\circ} \mathrm{C}^{2 \mathrm{~s})}\right)$ 。

ピクラートをアンモニア水で分解し, 純粋なカダレン [15 b] を得た。bp $127 \sim 128^{\circ} \mathrm{C} / 4 \mathrm{mmHg}$ (文献值 bp $137^{\circ} \mathrm{C} / 5 \mathrm{mmHg}^{20)}$ ), bp $155 \sim 156^{\circ} \mathrm{C} / 11 \mathrm{mmHg}^{2 \mathrm{~s})}$ ), $d_{4}^{20} 0.9754$ (文献值 ${ }^{20)} d_{4}^{10} 0.9847$ ), $n_{\mathrm{D}}^{20} 1.5863$ (文献值 $\left.n_{\mathrm{D}}^{10} 1.5910^{2 \theta}\right), n 191.582^{2 a)}$ )。IR は文献
值 ${ }^{5 b)}{ }^{10)}$ と一致した。NMR : $1.39 \mathrm{ppm}$ (二重線, $6 \mathrm{H}, \mathrm{C}_{\mathrm{CH}_{3}}^{\mathrm{CH}_{\mathbf{3}}}$ ), 2. $56 \mathrm{ppm}$ (一重線, $3 \mathrm{H}, \beta-\mathrm{CH}_{\mathrm{g}}$ ), $2.65 \mathrm{ppm}$ (一重線, $3 \mathrm{H}, \alpha-$ $\mathrm{CH}_{3}$ ), $3.74 \mathrm{ppm}$ (多重線, $1 \mathrm{H},-\mathrm{CH}$ ) , 7.14 8.03 ppm (多重

線、 $5 \mathrm{H}$ ，芳香環ブロトン)。

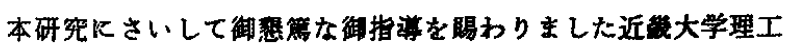
学部平尾子之吉教授に愿く御礼申し上げます。

10) B. A. Nagasampagi, Sukh Dev, Tetrahedron, 22, 1960 (1966).

\section{Synthesis of Cadalene and 1,4,6-Trimethylnaphthalene \\ Kazuo Adachi \\ Osaka Institute of Technology; Omiya, Asahi-ku, Osaka-shi, Japan}

Cadalene, a dehydrogenation product of some sesquiterpenes, was synthesized as follows. $p$-Methylacetophenone [1] was converted into 4-( $p$-tolyl) valeronitrile [9] passing through diethyl 2-(1-p-tolylethyl)malonate [4] (bp $142^{\circ} \mathrm{C} / 2 \mathrm{mmHg}$ ). The action of Grignard reagent on [9] yielded 2-methyl-6-( $p$-tolyl)-3-heptanone [ $12 \mathrm{~b}$ ] $\left(17.4 \%\right.$, bp $154 \sim 165^{\circ} \mathrm{C} / 15 \mathrm{mmHg}$, which was cyclized to 1,6 -dimethyl-4-isopropyl-1, 2, 3, 4-tetrahydronaphthalene [14 b] passing through the alcohol $[13 \mathrm{~b}]$. Cadalene $[15 \mathrm{~b}]$ was obtained by dehydrogenation of $[14 \mathrm{~b}]$ and also of the isopropylation product of 4,7-dimethyl-1, 2,3,4-tetrahydronaphthalen-1-one [11] with sulfur. Similarly, 5-( $p$-tolyl)-2-hexanone $[12 \mathrm{a}]\left(36.8 \%\right.$, bp $\left.110 \sim 115^{\circ} \mathrm{C} / 4 \mathrm{mmHg}\right)$ afforded $1,4,6-$ trimethylnaphthalene $[15 \mathrm{a}]$.

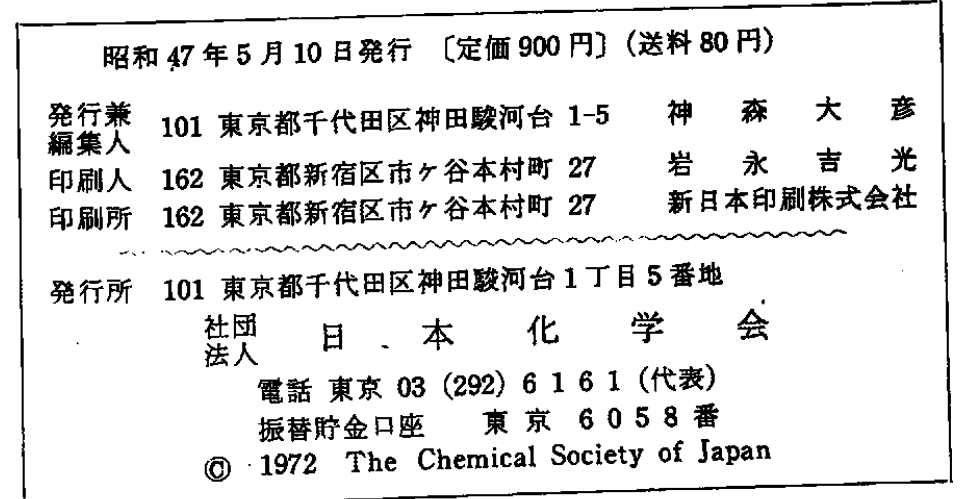

落丁，乱丁がありましたときは拈目に招申し出ください。お取りかえいたします。 